\title{
La reivindicación de la independencia editorial ante las políticas públicas del libro: ¿qué impacto?
}

\section{La revendication de l'indépendance éditoriale face aux politiques publiques du livre}

\author{
Luc Pinhas \\ Université Paris 13 / Labsic \\ pinhas.luc@wanadoo.fr
}

\section{Resumen}

La reivindicación de los editores independientes, a menudo organizados en colectivos, se ha ido fortaleciendo en los últimos quince años, sobre todo en las regiones latinoamericana y francófona. Ésta se inscribe en un contexto de globalización liberal y financiera, sustentada en la defensa de la "bibliodiversidad" - neologismo que ha experimentado una propagación muy rápida en el espacio público- y que actualmente ha sido recogido por los responsables políticos y los medios de comunicación. De esta manera, los editores independientes han contribuido a sensibilizar a los gobiernos y las autoridades locales respecto a la cuestión de la diversidad cultural, alertándoles sobre la necesidad de desarrollar políticas específicas para el libro. Los resultados concretos son innegables, aunque diferenciados según cada país.

Palabras Clave: Edición, biblioteca, políticas públicas, independencia, bibliodiversidad.

\section{Résumé}

La revendication des éditeurs indépendants, souvent rassemblés en collectifs, s'est affirmée au cours des quinze dernières années, tout particulièrement dans les espaces latino-américain et francophone. Elle s'inscrit, dans le contexte de la mondialisation libérale et financière, au nom de la défense de la «bibliodiversité », néologisme qui a connu une diffusion extrêmement rapide dans l'espace public et est aujourd'hui repris par le monde politique et médiatique. Les éditeurs indépendants ont ainsi contribué à sensibiliser les gouvernements et pouvoirs locaux à la question de la diversité culturelle et les ont alertés sur la nécessité de mettre en œuvre et/ou de développer des politiques spécifiques du livre. Les résultats concrets sont indéniables, bien que contrastés selon les pays. 
Mots Clés: Édition, librairie, politiques publiques, indépendance, bibliodiversité.

El nacimiento de la reivindicación pública de la independencia editorial, así como la consecuente constitución de diversos colectivos de editores independientes, a través de diferentes áreas geográficas y lingüísticas, en el curso de los diez a quince últimos años se inscriben en un contexto histórico, político, económico y cultural muy específico: el del potente ascenso de la mundialización bajo la dirección del liberalismo económico y financiero, tal como se manifiesta con la creación, en 1995, de la Organización Mundial de Comercio (OMC) y la voluntad norteamericana de liberalizar los servicios al igual que las mercancías. El de la aceleración y visibilidad aumentada de la concentración internacional en los dominios de la producción, de la distribución, de la promoción y de la venta del libro y, más en general, de los bienes culturales. Aquel, por último, de una inquietud difusa pero cada vez más compartida en el mundo, en cuanto a las posibilidades de preservar, o aún extender, las diversidades culturales ante las tendencias uniformadoras acarreadas por la nueva situación internacional que acabamos de recordar brevemente.

Por cierto, el mundo del libro, entre los sectores culturales, no es el único afectado por esta preocupación acentuada que toca también a muchas organizaciones sociales, como lo muestra el despliegue, en la segunda mitad de los años 90, del movimiento del "altermundialismo" en el que participan, por ejemplo, numerosos profesionales del cine. Es cierto también que la demanda de "excepción cultural" que se expresa no surge ex nihilo en ese momento, sino que fue precedida, aunque el concepto mismo no fuera empleado, de otros momentos fuertes y precursores. Pensemos, solo en el caso francés, en la virulenta oposición del mundo cinematográfico a los acuerdos BlumByrnes en la posguerra, o también en los debates de los años 70 que culminaron con el voto de la ley Lang, a menudo calificada con posterioridad como ley de excepción cultural o también, a veces, como ley de desarrollo durable.

Todo esto no impide que el surgimiento de la reivindicación de independencia, a fines de los años 1990, por parte de una franja notable de actores de la edición y la librería, así como el despliegue en el espacio público de un nuevo término, destinado a precisar el sentido del combate planteado -aquí quiero evidentemente hablar de la "bibliodiversidad" - se dieran en primer lugar como objetivo el llamar la atención de los poderes públicos y más ampliamente, la atención del propio gran público culto sobre la especificidad del libro como bien cultural y objeto investido de espíritu, según la definición kantiana, así como llamarlos a tomar las medidas de regulación necesarias para contrarrestar el solo juego del mercado económico y financiero en ese plano, y favorecer de ese modo la expresión de la diversidad. Para no tomar más que un solo ejemplo latinoamericano, una de las últimas acciones realizadas por la Liga Brasileña de Editores Independientes (LIBRE) que reúne un centenar de miembros, 
en asociación con la Asociación Nacional de los libreros y la Cámara Rio-Grandense del Libro, ha sido la de interpelar, en una carta abierta de abril de 2011, al Ministro brasileño de Cultura, para recordarle los compromisos electorales de la Presidenta Dilma Rousseff recientemente electa y proponerle un "Programa de defensa de la bibliodiversidad", detallado en catorce medidas concretas.

Parece legítimo, entonces, una decena de años después del despliegue de las primeras acciones, comenzar a preguntarse si las iniciativas impulsadas por los independientes, tanto editores como libreros, han logrado un impacto, y cuál sería, tanto sobre la visibilidad y el reconocimiento en el espacio público de esta franja de actores plurales, como sobre el devenir de las políticas públicas sobre el libro, al menos en ciertas áreas geográficas o lingüísticas. Para hacerlo, nos proponemos en primer lugar recordar las circunstancias en las cuales se inserta la instalación de los primeros colectivos de editores independientes y la difusión del concepto de "bibliodiversidad". Enseguida, nos dedicaremos a precisar las repercusiones en el espacio público del activismo desplegado en ese campo. Estudiaremos, finalmente, esforzándonos para no ceder a un determinismo de baja categoría, la evolución de las políticas públicas del libro en los dos espacios específicos en que la reivindicación de la independencia se expresó más particularmente y ha podido encontrar un cierto eco, el de América Latina, hispano-hablante y luso-hablante, y aquel de la francofonía. La hipótesis mínima que puede plantearse es que el movimiento de la independencia no solo ha contribuido a sensibilizar a los gobiernos y poderes locales al tema de la diversidad cultural, sino también los ha incitado a considerar la instalación o reactivación de políticas públicas del libro.

\section{EL SURGIMIENTO DE LA REIVINDICACIÓN DE LA INDEPENDENCIA EDITORIAL}

América Latina, precisamente, ve nacer, a finales de los años 1990, los primeros colectivos de editores que reivindican su independencia. Así, desde 1998, tres editoriales, LOM en Chile, Trilce en Uruguay yERA en México, asociados a Txalaparta, del país vasco español, toman nota de la similitud de sus concepciones editoriales y se asocian bajo la bandera de "Editores Independientes" para desarrollar proyectos de coedición y favorecer la visibilidad de sus obras en un área hispanohablante caracterizada por la fragmentación de los mercados del libro. Tras ellos y siguiendo su ejemplo, los editores chilenos deciden organizarse, al año siguiente, en una Asociación de los Editores Independientes de Chile (EDIN) que se abrirá más ampliamente en 2003 a los editores llamados autónomos y a los editores universitarios bajo la

1 http://www.editoresindependientes.com 
denominación de "Editores de Chile"2. Esos impulsos iniciales no dejan de producir su efecto a través de toda América Latina. Uno a uno se instalan, en el transcurso del primer decenio de los años 2000, diferentes colectivos en los diferentes países de la zona: la Liga Brasileña de los Editores en 2002, la Alianza de los Editores Mexicanos Independientes (AEMI) en 2004, la Alianza de los Editores Independientes de Argentina por la Bibliodiversidad (EDINAR) en 2006, la Alianza Peruana de los Editores Independientes, Autónomos y Universitarios (ALPE) en 2007, la Red de Editores Independientes Colombianos (REIC) en 2008, mientras por su lado editores madrileños fundan, en 2003, un colectivo llamado "Bibliodiversidad" ${ }^{3}$. Un colectivo de editores venezolanos se encuentra en camino a su constitución en 2012.

Es verdad que entretanto se realizó en Gijón, España, en el mes de mayo del 2000, un primer gran encuentro de editores independientes, de América Latina pero también de otras áreas geográficas, reunidos por iniciativa de la Biblioteca Intercultural para el Futuro, programa de la fundación de derecho suizo Charles Léopold Mayer, de donde nacerá dos años más tarde en París la Alianza Internacional de Editores Independientes, con el apoyo de la Unesco, el Banco Interamericano de Desarrollo y del CERLALC ${ }^{4}$. Es en el contexto de esta reunión que se discuten el rol y el porvenir de la edición independiente y se debaten propuestas a favor de la diversidad cultural y el diálogo intercultural, se emplea por primera vez el concepto de "bibliodiversidad", introducido por los responsables de la editorial chilena LOM. Al parecer es efectivo, aunque los editores del colectivo madrileño "Bibliodiversidad" también reivindican su paternidad, que el concepto encuentra su origen en el entorno de la edición independiente chilena. Con más precisión, si seguimos el estudio de María Eugenia Domínguez Saul (2010, p. 265), habría sido creado a fines de los años 1990, en el transcurso de un comité editorial de la editorial RIL, por analogía con la biodiversidad, particularmente amenazada en ese país, antes de ser retomado por los editores reunidos en el seno de EDIN. Como sea, la dimensión comunicacional del concepto es tal que su uso comienza a expandirse fuera de la sola área hispanohablante de América Latina. La Alianza de los Editores Independientes lo convierte enseguida, desde su creación, en la punta de lanza de su accionar y se esfuerza en nutrirlo de contenido teórico y operacional, particularmente luego del segundo encuentro que se produce en Guadalajara, México, en 2005, bajo el nombre de "Los Editores Independientes del Mundo Latino y la Bibliodiversidad", del cual surgirá un texto colectivo titulado "Palabras y Actos por la Bibliodiversidad" (2006).

\footnotetext{
2 http://www.editoresdechile.cl

3 http://www.oei.es/fomentolectura/sociedad_lectora_biodiversidad_gutierrez.pdf

4 Centro regional para el Fomento del libro en América Latina y el Caribe, organismo intergubernamental creado por iniciativa de la Unesco en 1971 con sede en Bogotá (http://www. cerlalc.org/)
} 
¿Por qué esta emergencia pionera se produce, en ese momento, en América Latina? Sin duda, algunos elementos de respuesta pueden ser avanzados. En primer lugar, el derrumbe una a una de las dictaduras en Uruguay, Argentina, Brasil y Chile, y la toma de conciencia vinculada al surgimiento del altermundialismo favorecieron, durante los años 1990, la apertura de nuevos espacios de libertad y una renovación de las ciencias sociales y humanas en los países latinoamericanos. Enseguida, sobre ese terreno ahora más propicio toma su impulso una generación joven de editores locales (mientras que asistíamos a un reordenamiento de los más antiguos), preocupados en valorizar los particularismos culturales, de hacer oír las voces locales y, sobre todo, manifestar su resistencia ante los procesos de desterritorialización inducidos por el dominio aplastante sobre todo el subcontinente de los grupos editoriales transnacionales, españoles en primer lugar, pero también norteamericanos, franceses o alemanes. Es muy notable, por otro lado, que las redes hispanohablantes se hayan abierto, en el curso de los últimos años, no solo a los editores independientes, sino también a los calificados como "autónomos" tanto como a los editores culturales, es decir al conjunto de los editores culturales locales ${ }^{5}$. Este fenómeno se produce hoy en Quebec. En fin, el avance del librecambismo, presionado por la firma de diferentes tratados comerciales, MERCOSUR a partir de 1991, ALENA 6 en 1994, después CAFTA-DR ${ }^{7}$ en 2004, si bien podría parecer a priori favorecer una circulación más amplia del libro en la zona referida, se puede ver también como una creciente amenaza en relación a la especificidad de los productos culturales, tanto más que no existen, en la mayoría de los países de la zona, políticas elaboradas en cultura y sobre todo para el libro y la lectura. Es, por otro lado, ciertamente una de las razones que impulsaron, por ejemplo, a los editores independientes chilenos a contribuir, entre muchos otros actores culturales, a la creación de la Coalición Chilena por la Diversidad Cultural, siguiendo el ejemplo de la que anteriormente se instaló en Canadá, precisamente a fin de proteger la posibilidad de políticas culturales públicas.

Más allá de América Latina, el despliegue de una nueva generación de "jóvenes" editores que se consideran primero como actores locales, culturales y críticos, puede ser considerada como la característica principal de la extensión de la reivindicación de la independencia editorial. Es sobre todo el caso en la Francofonía del Sur,

5 Este acercamiento provoca, sin embargo, dificultades. Así, el colectivo peruano acaba (2012) de cambiar su nombre para convertirse en Editores Independientes del Perú, señalando así una separación entre los editores independientes y los editores universitarios, cuyas lógicas son percibidas como divergentes (sobre todo a causa de las subvenciones recibidas por los editores universitarios, o también por lo específico de su circuito de distribución)

6 En inglés North American Free TradeAgreement, NAFTA, en español Tratado de Libre Comercio de América del Norte

7 DominicanRepublic-Central America Free TradeAgreement, Acuerdo de Libre Comercio de América Central y República Dominicana 
donde la edición local africana, prácticamente inexistente hace una quincena de años, salvo raras excepciones, empieza a buscar su vía a través del apoyo mutuo en sus esfuerzos y en la demanda de regulación por parte de los poderes públicos. En la propia Francia, en la huella de las ediciones Liber-Raisonsd'agir, creadas por el sociólogo Pierre Bourdieu, se lanzan en los años 1990, múltiples estructuras que se consideran como ediciones críticas. Sus actores se proponen conducir una reflexión sobre sus prácticas y las condiciones del mercado del libro, confrontadas a los fenómenos de concentración y de internacionalización, que se concretiza por la realización de diferentes manifestaciones y la publicación de varios ensayos. A ese fin, la publicación en la editorial La Fabrique de la obra de André Schiffrin La edición sin editores, rápidamente traducida a múltiples idiomas, ha jugado sin duda un rol de catalizador de la reivindicación independiente. En Quebec, por último, donde la excepción cultural ha sido parte activa de la renovación que ha conocido La Bella Provincia en el curso de los últimos cincuenta años, los límites de las políticas públicas del libro, confrontadas a la mundialización, han conducido, estos últimos años, a nuevas formas de agrupación que fluctúan entre reivindicación de la independencia y reivindicación del rol jugado por los editores culturales. Una agrupación de editores literarios independientes (RELI) fue creada primero en 2006, bajo la batuta de cuatro editores simbólicamente importantes, Boréal, Fides, Hurtubise y QuébecAmérique. Rápidamente, sin embargo, se amplió y transformó para convertirse en Agrupación de Editores Literarios de Quebec (GELi) que reúne más de una treintena de editores. Su rol, tal como es indicado en la página de presentación de su sitio es de defender "el vigor y la influencia" del libro cultural "en la plaza pública" y de destacar "los intereses de la bibliodiversidad ( ... ) representados demasiado blandamente ante los organismos gubernamentales" ${ }^{\prime}$. De manera bastante evidente, el GELi se ha aproximado a otra agrupación, esta vez de libreros, nacida en 2007, los Libreros Independientes de Quebec (LIQ) que reúnen hoy más de 90 establecimientos, para demandar ante los poderes públicos, con el conjunto de las asociaciones profesionales del libro, una reglamentación sobre el precio de las novedades?.

\section{UNA VISIBILIDAD ACRECENTADA EN EL ESPACIO PÚBLICO...}

¿Se puede, con todo esto, medir el impacto de la reivindicación de la independencia editorial sobre las políticas públicas del libro? La respuesta es, por cierto, delicada de

8 http://legeli.wordpress.com/info/

9 Ver el sitio dedicado por el mundo del libro quebequense a esta batalla: http://noslivresajusteprix. $\underline{\mathrm{com} /}$ 
dar. Podemos, no obstante, constatar, en un primer tiempo, que las problemáticas de la independencia han encontrado rápidamente una cierta visibilidad en el espacio público. La noción misma de independencia, que era ampliamente ignorada hace solo una quincena de años (salvo en acepciones bien distintas, en el campo del cine, por ejemplo) se encuentra hoy ampliamente reconocida, tanto por el medio profesional del libro, incluyendo en él el mundo de la lectura, como por los actores políticos, aunque se exponga a veces a ser apropiada para fines de promoción y autovalorización. Esta ha sido retomada también por los libreros, cuya existencia misma, para varios de ellos, se encuentra amenazada en la situación actual, favoreciendo así una saludable convergencia de intereses entre dos eslabones cuyas relaciones han sido desde hace bastante tiempo ambivalentes. Numerosas acciones, al menos en los mundos francófonos e hispanoparlantes, han permitido alertar a la opinión pública e interpelar a los poderes públicos, a través de obras, de cartas abiertas a los ministros de cultura, a candidatos en elecciones o a las cámaras legislativas. Peticiones, por ejemplo, de tarifas postales preferenciales, o aún de debates con ocasión de diversos salones o ferias del libro. La prensa de información se ha convertido además después de algunos años en su transmisora, participando así en un movimiento de lobbynada despreciable a favor de la independencia editorial, que produce en ocasiones sus frutos. Así, para no tomar más que un ejemplo, es el ex vice-presidente de la ALPE quien fue elegido como coordinador para el desarrollo de la lectura en el Ministerio de la Cultura peruano. En otros lados, informes son encomendados por las más altas autoridades y se produce la sensibilización de las administraciones del libro a las problemáticas de la diversidad.

De su lado, el neologismo "bibliodiversidad" ha adquirido de manera fulgurante derecho de entrada y se encuentra también empleado de forma recurrente, tanto en numerosos documentos profesionales como en discursos políticos o incluso en la prensa para el gran público y en Internet, al menos en las áreas francófona, lusoparlante e hispanoparlante. Su uso comienza a expandirse también en el mundo angloparlante ${ }^{10}$. El riesgo, por cierto, es allí también de una apropiación-pretexto del concepto por los políticos, o aún por los grandes actores de la edición, con el riesgo de diluir o transformar su sentido.

En Francia, el periodista Alain Beuve-Méry divulgó en el cotidiano Le Monde, en abril de 2007, la carta abierta "Un llamado a favor de la bibliodiversidad" dirigida por la Alianza de los editores independientes a los candidatos a la elección presidencial, en un articulo titulado "Algunas ideas para el próximo gobierno" ${ }^{11}$. La candidata que

10 Ver, por ejemplo, el sitio norteamericano «BooksontheNightstand» (http://booksonthenightstand. com/?s=bibliodiversity) y también "The Boston bibliophile» (http://www.bostonbibliophile. com/2012/01/reading-goals-for-2012-and.html)

11 Ver: http://www.alliance-editeurs.org/-revue-de-presse- 
perdió las elecciones, Ségolène Royal, es enseguida una de las primeras en emplear el término para justificar la puesta en marcha de un eje de política pública regional del libro. Lo hace en enero de 2008, con ocasión del discurso de presentación de la Carta "Leer en Poitou-Charentes", que concede un sello de calidad a las "librerías independientes regionales de excelencia” de la región que ella preside y que está dotada de una asignación financiera, renovable, de 1,5 millones de euros por tres $\operatorname{años}^{12}$. Se debe notar, por otro lado, que las librerías calificadas deben comprometerse, principalmente, a "entregar una atención particular a las producciones de editores y a las obras de autores de Poitou-Charentes" ${ }^{13}$. El concepto se encuentra empleado otra vez en la nueva versión del "Protocolo de acuerdo sobre los usos comerciales de la edición con la librería" ${ }^{14}$, firmado el 26 de junio de 2008 por el Sindicato Nacional de la Edición (SNE), el Sindicato de la Librería Francesa (SLF) y el Sindicato de Distribuidores de Entretenimientos Culturales (SDLC). Desde entonces, se ha generalizado.

En Brasil, varias cámaras sindicales de editores y de libreros han retomado el término "bibliodiversidad", en particular la de Bahía, en apoyo a la puesta en marcha de programas de defensa del libro de producción regional. La Universidad Federal de Río Grande do Sul, en Porto Alegre, por su parte, ha inaugurado en 2010 un plan de formación continua llamado "Los mediadores de lectura y de la bibliodiversidad"15, destinado a profesores y responsables de bibliotecas escolares, programa ampliamente repercutido por múltiples blogs. Además, la LIBRE organiza anualmente desde 2001 una feria del libro, "La primavera del libro", que tiene lugar en Rio de Janeiro y Sao Paulo y que asegura una efectiva visibilidad a las problemáticas de la independencia y la bibliodiversidad.

Por otro lado, el año 2010 ha visto el lanzamiento a través de toda América Latina, con el impulso del editor argentino Guido Indij (La Marca Editora), de la Jornada Internacional de la Bibliodiversidad (El día B) que desde entonces se celebra cada 21 de septiembre, día de la primavera en el hemisferio sur. La primera edición fue un suceso inmediato a lo largo y ancho del subcontinente, retomado en Argentina primero, pero también en Chile, México, Perú, Paraguay, Colombia, República

\footnotetext{
12 "Es en ese plan regional que se inscribe la firma de hoy, que permitirá sostener eficazmente la creación y la bibliodiversidad (subrayado en el original) favoreciendo la profesionalización y las condiciones de existencia y el desarrollo de esas librerías que privilegian el comercio de consejo" (www.poitou-charentes.fr/region/discours/archives)

13 Ver: http://www.poitou-charentes.fr/services-en-ligne/guide-aides/-/aides/detail/126

14 "El presente protocolo se inscribe en el marco establecido por la ley del 10 de agosto de 1981 para defender la bibliodiversidad y la creación editorial. En ese marco, sus signatarios destacan la importancia de ésta ley y se comprometen a defenderla y a promover su aplicación"(www.syndicatlibrairie.fr/fr/accords_professionnels)

15 http://www6.ufrgs.br/mediadoresdeleitura/edital1.pdf
} 
Dominicana, Brasil y hasta en España por decenas de medios, diarios nacionales, radios o sitios de Internet. La segunda y tercera ediciones han permitido a esta manifestación tocar otros continentes y países, Italia, África sub-sahariana, el Magreb, Madagascar, Turquía, África del Sur y hasta India y Australia ${ }^{16}$. En ese contexto, y a modo de ejemplo, en septiembre de 2012 millares de libros han sido "liberados" en espacios públicos de Bogotá y otras ciudades colombianas, así como en las paradas de los transportes rurales de Antananarivo, en Madagascar, o aún sobre los escaños públicos de Estambul, se lanzaron campañas de difusión de marca-páginas, de autoadhesivos y de afiches, un aperitivo de lecturas poéticas fue organizado en la plaza de los lectores del Museo del Libro de Buenos Aires, y los editores de la red arabo-parlante de la Alianza organizaron, en ocasión del último Salón Internacional del Libro de Argel (20-29 de septiembre 2012) un “concurso del mejor lector”. Es interesante notar que la Alianza de Editores Independientes de lengua española fue invitada de honor en la Feria del Libro de La Paz 2012, en Bolivia (19-20 de agosto de 2012).

\section{¿PARA QUÉ EFECTOS CONCRETOS?}

Queda aún por examinar qué efectos concretos han podido tener las presiones de los editores independientes, con frecuencia acompañados en esas actividades por las asociaciones de libreros, sobre las políticas públicas del libro impulsadas desde hace una decena de años. Cuatro aspectos al menos pueden ser tomados en cuenta a través de esa mirada: la propia determinación de políticas públicas, la cuestión de un precio fijo para el libro, las acciones de apoyo a los editores, sobre todo en términos de visibilidad internacional, de ayuda a la coedición e incluso a la traducción, y por último las políticas de compras públicas de libros.

La sensibilización de los gobiernos y poderes locales a la necesidad de instalar o reactivar políticas públicas específicas del libro para defender y desarrollar la bibliodiversidad parece haber producido en parte sus frutos en un cierto número de países. Esta constatación no significa, de cualquier forma, que hayan tomado medidas efectivas en todos los casos. Así, si tomamos el ejemplo chileno, parece innegable que la acción de EDIN, conjugada con los otros actores sociales del libro ha contribuido a la creación de un Consejo Nacional de la Cultura y las Artes que tiene rango de ministerio y en el cual EDIN es representado actualmente por su vicepresidente, y a la adopción en 2006, por el gobierno de Michelle Bachelet, de un

16 Para el detalle de las acciones y reseñas periodísticas, ver: http://eldiab.org/ et http://www. alliance-editeurs.org/ 
Programa de Política Nacional del Libro y de la Lectura. Este, si lo vemos bien, retoma ampliamente las 39 proposiciones adelantadas el año anterior (al momento de la elección presidencial) por EDIN en un documento público. Seis años más tarde, sin embargo, la aplicación de ese programa parece claramente deficiente, salvo, en alguna medida, en el campo de la promoción de la lectura ${ }^{17}$. En Perú, la Ley del Libro, votada en 2003, está lejos de haber realmente permitido todos los efectos esperados, por falta de aplicación. Así, la instauración de tarifas postales preferenciales no es respetada por los Correos peruanos, lo que empuja al ALPE a solicitar una modificación de la ley ${ }^{18}$. En compensación, el libro es exonerado del pago del IVA, que no es el caso, por ejemplo, de Chile, donde se le aplica la totalidad del impuesto. En África francófona, otro caso, la acción de los editores locales, varios de los cuales son miembros de la asociación Afrilibros, creada en 2002, y de la Alianza de Editores Independientes, ha permitido hacer tomar consciencia a los diferentes gobiernos, al menos en algunos países (Costa de Marfil, Mali, Madagascar), de la importancia de asegurar un puesto a los editores nacionales y regionales en el mercado del libro escolar. La propia Organización Internacional de la Francofonía (OIF) ha modificado su política de apoyo en el curso de los últimos años. La organización ha empezado a condicionar sus ayudas a la puesta en marcha de políticas nacionales del libro y de la lectura y a la integración de los editores locales a las licitaciones en el mismo campo de la edición escolar. Apoya igualmente la difusión de la informática, financiando, por ejemplo, el reclutamiento de voluntarios civiles encargados de esta dimensión en las estructuras editoriales. En Francia, tal vez, es más difícil decir cuál es la parte de la presión ejercida por los editores y los libreros independientes sobre el devenir de las políticas públicas del libro. Uno puede, sin embargo, pensar que la efervescencia suscitada alrededor de la independencia y la bibliodiversidad por los múltiples escritos, debates, cartas abiertas, no ha ocurrido sin impacto, tanto a nivel regional como nacional. Hemos recordado más arriba las líneas de acción puestas en práctica en Poitou-Charentes, que complementan regionalmente un programa nacional de apoyo a la librería independiente, administrado por el CNL e instalado en $2008^{19}$. En Île-de-France, la alternancia política de 2004 ha visto a la región afirmar sus competencias en materia de libro y lectura para desarrollar diferentes acciones de apoyo. Su programa, tal como uno puede leerlo en el sitio del consejo regional ${ }^{20}$ hace referencia directa a la

17 Cf. el memorándum dirigido al autor de este artículo por Juan Carlos Sáez, Vice-Presidente de EDIN, el 21 septiembre 2012

18 Ver el texto completo de la demanda de la ALPE: http://alpe.wordpress.com/2007/09/22/ modificatoria-de-la-ley-del-libro/

19 http://www.centrenationaldulivre.fr/?-Le-label-Librairie-Independante-de-

20 http://www.iledefrance.fr/missions-et-competences/culture-tourisme-sports/la-culture-et-lepatrimoine/le-livre-et-ledition/ 
bibliodiversidad y se propone apoyar a la librería y a la edición independiente a través, por ejemplo, de una fuerte presencia en el Salón del Libro de París. Habría que hacer notar también que el programa para el libro y la lectura de François Hollande durante la última campaña presidencial de la primavera de 2012, detallado por Aurélie Filipetti, actual Ministra de Cultura, consagra una sección entera al apoyo a la edición y la librería independiente. Retoma, en suma, varias de las proposiciones adelantadas anteriormente por la Alianza de los editores independientes en una carta abierta a los candidatos, por ejemplo en materia de reforma a los códigos de los mercados públicos o de creación de tarifas postales preferenciales. Es verdad que uno de los consejeros cercanos de la señora Filipetti es un ex miembro del equipo de la Alianza. En fin, uno puede fácilmente pensar que los colectivos de editores independientes han contribuido considerablemente, entre otros muchos actores, a la adopción por la UNESCO de la Convención por la Diversidad Cultural de 2005. Ellos se esfuerzan también, en diferentes países, incluido Chile, a su ratificación efectiva.

La adopción de medidas a favor de un precio único del libro es, por otro lado, parte de las reivindicaciones recurrentes de los editores y libreros independientes. Es inevitable constatar que este tema se ha vuelto central en varios países en el curso de los diez últimos años. Una ley en este sentido fue adoptada en Argentina en 2002, mientras que en México no fue sino a la salida de una larga lucha emprendida por los independientes que se votó la ley por el desarrollo de la lectura y el libro del 24 de julio de 2008, que instituye un precio fijo. Un primer texto había sido votado, en efecto, en 2006, pero había sido objeto de un veto del presidente de la época, Vicente Fox, y solo fue tras la elección de Felipe Calderón que la situación pudo evolucionar favorablemente. En Brasil, donde el tema está en debate hace años, la Presidenta Dilma Roussef se pronunció por el voto de una ley en el transcurso de la campaña presidencial, pero hasta ahora no se ha presentado ningún texto ante el parlamento brasileño, tal vez por la falta de una red suficientemente desarrollada de libreros independientes. En Suiza, el intenso lobby realizado por los profesionales romandos, incluyendo el uso de la obra de Markus Gerlach Proteger el libro (2006), se selló finalmente con un fracaso en los meandros del proceso de adopción propio de la Confederación Helvética. Una ley federal sobre la reglamentación del precio fue efectivamente adoptada, pero luego rechazada con ocasión de una votación popular, por veinte cantones, principalmente germánicos, sobre veinte y seis. En Quebec, como ya hemos visto, el conjunto de los profesionales del libro se movilizan hace meses a favor de una reglamentación de las novedades y tienen grandes esperanzas en el nuevo gobierno surgido del Partido Quebequense. En Italia, la presión de los profesionales, y en particular de la Federación Italiana de Editores Independientes 
$\left(\right.$ FIDARE $\left.^{21}\right)$ culminó con el voto de una ley, llamada "Ley Levi" en julio de 2011. Este nuevo compromiso público, aunque la ley parezca imperfecta, ha incitado a los libreros ingleses a reclamar, a su vez, en el otoño 2011, la vuelta a un precio fijo en Gran Bretaña ${ }^{22}$.

Los últimos años han visto, igualmente, los diversos poderes públicos comenzar a tomar medidas, cierto que aún bien fragmentarias y modestas, de apoyo directo a los editores. Así, en Argentina, la ciudad de Buenos Aires adoptó en 2005 un programa, "Opción libros" (O también "Programa de promoción de la diversidad bibliográfica"), de apoyo a la edición y a la librería independiente que pasa por la publicación de catálogos y de anuarios, y también por operaciones específicas y reconocibles, como "La noche de los libreros". Por otro lado, la invitación de honor a Argentina a la feria de Frankfurt en 2010 impulsó al gobierno argentino a lanzar un programa de traducción, "Proyecto Sur", referido a 250 obras. En Colombia, el estado sostuvo en un primer tiempo la creación de la REIC y solicitó a la fundación de derecho privado Corona de reforzar el colectivo sosteniendo los proyectos de una docena de editores. Enseguida puso en marcha un programa de consolidación de las estructuras independientes que pasa por el desarrollo de la formación profesional, un plan de comercialización de obras, la instalación de un sitio web y compras por parte de las bibliotecas públicas. En Chile, me parece, diferentes proyectos parciales han sidologrados, comola creación de una revista dedicada al libro chileno, el lanzamiento de programas de radio o incluso la puesta en marcha de eventos itinerantes para promover y vender los libros de editores independientes locales. En Benín, Afrilibros ha establecido una asociación con los correos locales para facilitar el transporte de libros. Por su lado, el Instituto Francés desarrolla un programa de ayuda a la cesión y coedición Norte-Sur en dirección de países de África, Magreb, El Líbano, el Caribe y el Océano Índico interesados en la adquisición de derechos de editores franceses en vista a publicaciones adaptadas a los precios del mercado local. Veintiséis proyectos han sido apoyados así, aunque el presupuesto asignado hubiera permitido varios más. La cooperación francesa, por medio del Instituto Francés interviene también en América Latina; de una parte, a través del apoyo a programas de ayuda a la introducción de obras francesas (Programa Victoria Ocampo en Argentina, Pablo Neruda en Chile, Alfonso Reyes en México, y Lautréamont en Uruguay), de otra parte, por medio de un programa regional de ayuda a la coedición de libros franceses por editores de diferentes países.

Finalmente, los editores independientes, particularmente en América Latina, luchan también para obtener una mayor consideración en los programas de compras públicas de libros, que son muy importantes en países como Chile, México y aún

21 http://www.fidare.it

22 http://www.livreshebdo.fr/actualites/DetailsActuRub. aspx?id=7423 
Brasil, y una presencia destacada en las bibliotecas. A veces obtienen resultados. Es el caso, especialmente, de Brasil, gracias a la acción de la LIBRE. El programa plurianual de compras de libros de literatura para los jóvenes de escuelas públicas (Programa Nacional de la Biblioteca Escolar, creado en 1997), largo tiempo monopolizado por los grandes grupos, reserva desde hace varios años un espacio mayor a los editores independientes, mientras que el Ministerio de la Cultura ha puesto en marcha un importante programa de apoyo a las bibliotecas públicas que favorece la bibliodiversidad, valorizando la producción literaria regional. En Chile, similarmente, la presión de EDIN ha tenido por resultado un reequilibrio de las compras de libros para las bibliotecas escolares y públicas, entre los grupos transnacionales y los actores de la edición independiente. Lo mismo ocurre en México.

Para concluir, incluso si la situación continúa siendo muy insatisfactoria en numerosos países, el trabajo de los editores independientes parece comenzar a producir sus frutos y la dimensión de la bibliodiversidad parece más integrada en las reflexiones de los poderes públicos. Esto no quita que la presión de los grandes grupos y, ahora, sobre todo de los principales actores de la revolución informática, continúa haciendo pesar sobre la diversidad cultural amenazas más que tangibles. Dos eventos recientes nos llevan así a pensar de forma contradictoria. De un lado, el apoyo de Arnaud Nourry, presidente de Hachette Libro, a la solicitud de los profesionales quebequenses de una ley sobre el precio fijo de las novedades, como si el conjunto de los actores tradicionales del libro hicieran frente común ante los nuevos integrantes venidos de la informática, en primer lugar los "tres gorilas" (Apple, Google, Amazon); de otro lado, el informe de la Comisión suiza de la competencia, demandada tras el rechazo del pueblo suizo a aceptar la ley del precio único, que denuncia entendimientos ilícitos entre los principales distribuidores, (que son filiales de grandes editores franceses) y exige sanciones financieras, las que podrían llegar a $10 \%$ del total de las ventas realizadas en el país por las empresas acusadas. 